\title{
Myeloid-derived suppressor cells and myeloid regulatory cells in cancer and autoimmune disorders (Review)
}

\author{
PRINCE AMOAH BARNIE ${ }^{1,2}$, PAN ZHANG $^{1}$, HONGXIANG LV $^{1}$, DAN WANG $^{1}$, \\ XIAOLIAN $\mathrm{SU}^{1}$, ZHAOLIANG $\mathrm{SU}^{1,3}$ and HUAXI XU ${ }^{1}$ \\ ${ }^{1}$ Department of Immunology, School of Medical Science and Laboratory Medicine, Jiangsu University, Zhenjiang, \\ Jiangsu 212013, P.R. China; ${ }^{2}$ Department of Biomedical and Forensic Sciences, School of Biological Sciences, \\ University of Cape Coast, Cape Coast, Ghana; ${ }^{3}$ Department of Laboratory Medicine, \\ Affiliated Hospital of Jiangsu University, Zhenjiang 212001, P.R. China
}

Received September 23, 2015; Accepted October 17, 2016

DOI: 10.3892/etm.2016.4018

\begin{abstract}
Myeloid-derived suppressor cells (MDSCs) were originally described as a heterogeneous population of immature cells derived from myeloid progenitors with immune-suppressive functions in tumor-bearing hosts. In recent years, increasing number of studies have described various populations of myeloid cells with MDSC-like properties in murine models of cancer and autoimmune diseases. These studies have observed that the populations of MDSCs are increased during inflammation and autoimmune conditions. In addition, MDSCs can effectively suppress T cell responses and modulate the activity of natural killer cells and other myeloid cells. MDSCs have also been implicated in the induction of regulatory $\mathrm{T}$ cell production. Furthermore, these cells have the potential to suppress the autoimmune response, thereby limiting tissue injury. Myeloid regulatory cells (Mregs) are recently attracting increasing attention, since they function in proinflammatory and immune suppression in autoimmune diseases, as well as in various types of cancer. Currently, research focus is directed from MDSCs to Mregs in cancer and autoimmune diseases. The present study reviewed the suppressive roles of MDSCs in various autoimmune murine models, the immune modulation of MDSCs to $\mathrm{T}$ helper 17 lymphocytes, as well as the proinflammatory and immunosuppressive roles of Mregs in various types of cancer and autoimmune diseases.
\end{abstract}

Correspondence to: Professor Zhaoliang $\mathrm{Su}$ or Professor Huaxi Xu, Department of Immunology, School of Medical Science and Laboratory Medicine, Jiangsu University, 301 Xuefu Road, Zhenjiang, Jiangsu 212013, P.R. China

E-mail: szl30@yeah.net

E-mail:xuhx@ujs.edu.cn

Key words: myeloid-derived suppressor cells, myeloid regulatory cells, inflammation, autoimmune diseases, cancers

\section{Contents}

1. Introduction

2. Origin and subsets of MDSCs

3. Transcription factors associated with MDSC

4. MDSCs and cancer

5. MDSCs and autoimmune disorders

6. MDSCs and systemic lupus erythematosus (SLE)

7. MDSCs and rheumatoid arthritis (RA)

8.MDSCs and experimental autoimmune myocarditis (EAM)

9. MDSCs and experimental autoimmune encephalomyelitis (EAE)

10. MDSC-mediated suppression of $\mathrm{T}$ cell function

11. MDSCs and Th17 cells

12. MDSCs mediate Tregs expansion

13. Therapeutic potential of MDSCs in autoimmune disorders

14. Myeloid regulatory-mediated activation of $\mathrm{T}$ cell function in cancer and autoimmune models

15. Conclusion

\section{Introduction}

Myeloid-derived suppressor cells (MDSCs) represent a heterogeneous population of cells that accumulate during autoimmunity and other pathological conditions (1). The activation of MDSCs in pathological conditions leads to the upregulation of the expression of immune suppressive factors, resulting in MDSC-mediated suppression of $\mathrm{T}$ cell functions (2). Autoimmune diseases encompass a group of diseases which emanate from a dysregulated immune system that evokes a damaging attack on its own tissues (3). Patients with autoimmune disease present immune injury caused by autoreactive $\mathrm{T}$ cell activation and autoantibodies. The causes of immune system diseases include abnormal expression of major histocompatibility complex (MHC)/peptide complex molecules, immune tolerance and dysfunction of regulatory $\mathrm{T}$ cells (Tregs) among other reasons. Tregs are immunosuppressive $T$ cells that exhibit potential inhibitory effects on effector cells via the production of inhibitory cytokines, thereby interfering 
with the effector cell metabolism and killing effector cells by perforin and granzyme release (4,5). T helper 17 (Th17) cells, characterized by the production of interleukin-17 (IL-17) and other pro-inflammatory cytokines, have a defined role in the development of inflammatory and autoimmune pathologies. In recent years, MDSCs have been demonstrated to not only suppress the response of Th17 cells, but also mediate Treg expansion during autoimmunity and other pathological conditions (6). The unique roles of MDSCs in the development of the immunosuppressive network indicate that this cell population may have potential as a therapeutic modality in autoimmune diseases; however, MDSCs do not serve the same role in cancer. In various types of cancer, MDSCs are known to subvert host defense mechanisms, thereby promoting cancer progression $(2,7)$. The ability of MDSCs to suppress antitumor Th1 cells and cytotoxic T-lymphocytes (CTL) immune responses have been demonstrated to impact the immune system directly and indirectly (8). In recent years, the focus of research is gradually shifting from MDSC to the general category of myeloid regulatory cells (Mregs). The Mreg population of cells includes the MDSCs, regulatory dendritic cells (DCs), regulatory macrophages and subsets of granulocytes. The present study reviewed the suppressive roles of MDSCs in various autoimmune murine models, the immune modulation of MDSCs to Th17, as well as the proinflammatory and immunosuppressive roles of Mregs in cancer and autoimmune diseases. The study also aimed to highlight the harmful and potential beneficial roles of utilizing Mregs for therapeutic purposes in systemic autoimmune disorders.

\section{Origin and subsets of MDSCs}

MDSCs are a heterogeneous population of cells that consists of myeloid progenitor cells and immature myeloid cells. In healthy individuals, MDSCs are generated in the bone marrow and quickly differentiate into mature granulocytes, DCs or macrophages. However, under pathological conditions (such as cancer), various infectious diseases and certain autoimmune diseases, a partial block in the MDSC differentiation into mature myeloid cells results in the expansion of this cell population (2).

In mice, MDSCs are identified as cells that simultaneously express CD11b and Gr-1, which comprises by Ly-6C and Ly-6G. The CD11b $b^{+}$y- $6 G^{+}$Ly-6C high $^{\text {cells with }}$ monocytic-like morphology are termed monocytic MDSCs (M-MDSCs), whereas the CD11b $\mathrm{Ly}-6 \mathrm{G}^{+} \mathrm{Ly}-6 \mathrm{C}^{\text {low }}$ cells have a granulocyte-like morphology and are termed granulocytic MDSCs (G-MDSCs) (9). These two cell groups differ in functionality: G-MDSCs frequently inhibit T cell function through arginase-1 (ARG-1) enzyme activity, whereas M-MDSCs more commonly inhibit $\mathrm{T}$ cell functions via nitric oxide (NO) production (10-12). Interferon (IFN)- $\gamma$-mediated activation of MDSCs results in the upregulation of ARG-1 and NO production.

In humans, MDSCs are defined as cells that express CD33, but lack the expression of markers of mature myeloid and lymphoid cells (13). In recent years, studies have revealed that a number of markers, including $\mathrm{CD}_{11} \mathrm{~b}^{+}$and $\mathrm{CD}_{3} 3^{+}$, are associated with MDSC function in humans (14-16). The activation of MDSCs in pathological conditions leads to the upregulation of the expression of immune suppressive factors, including ARG-1 enzyme (encoded by the ARG-1 gene) and inducible NO synthase (iNOS; also known as NOS2), as well as an increase in the production of $\mathrm{NO}$ and reactive oxygen species (ROS). As a result, MDSCs potently suppress T cell responses and modulate the activity of natural killer (NK) and myeloid cells, and serve an important role in the development of the immunosuppressive network.

\section{Transcription factors associated with MDSCs}

Several transcription factors that are involved in the activation or generation of MDSCs have been previously identified (17). Certain transcription factors, including PU.1 (13), CCAAT/enhancer-binding protein- $\beta$ (C/EBP- $\beta)$ (18), and signal transducer and activator of transcription (STAT)1, STAT3 and STAT6 (19), are involved in the general myeloid cell lineage development, and therefore are also implicated in MDSC development and activation. Previous studies reported that $\mathrm{C} / \mathrm{EBP}-\beta$ promotes the generation of activated MDSC in vitro (20), while mice with $\mathrm{C} / \mathrm{EBP}-\beta$-cell deficiency cannot differentiate myeloid cells into MDSCs $(17,21,22)$. Notably, another study indicated that $\mathrm{C} / \mathrm{EBP}-\beta$ is not required for the generation of MDSC precursors, but rather the re-pooling of the granulocytes following neutropenia (23).

\section{MDSCs and cancer}

The majority of the current knowledge regarding the role of MDSCs in immune responses has originated from studies in the context of cancer. Studies have indicated that MDSC subsets are differentially regulated in tumor-bearing mice $(9,24)$. These ambiguities have often resulted in conflicting findings, which raises questions about the mechanisms of suppression and MDSC subsets to tumor specificity. Certain studies have attempted to elucidate these issues by analyzing the different subsets of MDSCs in different murine models. MDSCs in cancer patients and tumor-bearing mice have been reported to subvert immune surveillance by dampening $\mathrm{T}$ cell immunity $(14,25)$, thereby promoting cancer progression.

A study by Youn et al (9) reported that, although the number of MDSCs was significantly elevated in all 10 tumor models studied (including EL4 thymoma, Lewis lung carcinoma, B16F10 melanoma, MC38 colon carcinoma, C3 sarcoma, DA3 mammary carcinoma, 4T1 mammary carcinoma, CT26 colon carcinoma, Meth A sarcoma and ANV mammary carcinoma), the extent of MDSC expansion varied between different tumor models. Sarcomas demonstrated the lowest level of MDSC expansion, whereas colon carcinoma, thymoma and breast carcinoma showed high levels of expansion. In vitro data suggest that the level of MDSC expansion was determined by the nature of soluble factors produced by the tumors $(9,26)$.

Human MDSC phenotypes have yet to be fully described. In general, all human MDSCs are considered to express the common myeloid lineage marker CD33, with absent or low expression of MHC-class II (as would be detected on more differentiated myeloid cells) (26). Additional markers have been described, and may potentially represent different stages of MDSC development or completely independent populations of myeloid suppressor cells. Human MDSCs 
were induced in human solid tumors and characterized as distinct MDSC subsets: CD33 ${ }^{+} \mathrm{HLA}_{-} \mathrm{DR}^{\text {low }} \mathrm{HIF} 1 \alpha^{+} / \mathrm{STAT}^{+}$ and $\mathrm{CD} 11 \mathrm{~b}^{+} \mathrm{HLA}-\mathrm{DR}{ }^{\text {low }} \mathrm{C} / \mathrm{EBP}-\beta^{+}(26)$. Initial investigation on the production of myeloid cells in cancer patients revealed an increase in $\mathrm{CD}_{3} 3^{+} / \mathrm{CD} 34^{+} / \mathrm{CD} 15^{+}$lineage cells in patients with head and neck cancer (13). Certain more recent studies have also demonstrated the presence of a CD14 ${ }^{+}$subset of MDSCs in patients with melanoma and hepatocellular carcinoma, and this subset appears to inhibit immune cell function through L-arginine regulation (27-29).

\section{MDSCs and autoimmune disorders}

MDSCs have been suggested to participate in autoimmunity, and their roles in organ-specific autoimmunity, such as in the central nervous system, gut and liver, have been reviewed in a laboratory mouse model of autoimmunity (1). In vitro, the majority of the functional MDSC populations isolated from the autoimmune mouse model can suppress $\mathrm{T}$ cell proliferation via iNOS and the elaboration of NO. However, in vivo, MDSCs do not show adequate ability to prevent autoreactive $\mathrm{T}$ cell responses (30). This may be caused by the environment of autoimmunity, although this hypothesis needs to be investigated further. The present study aimed to review available studies on mouse models of various autoimmune diseases, and to discuss the suppressive roles of MDSCs and the possible role of Mregs in the proliferation of Th17 cells to promote disease severity in these murine models.

\section{MDSCs and systemic lupus erythematosus (SLE)}

SLE is a prototypical systemic autoimmune disorder, which is characterized by elevated levels of antinuclear antibodies and cellular infiltration of extensive organs, including the skin, kidney and heart. The immune complex deposition results in the compromise of the inflammatory system, which leads to tissue damage and inflammation via the activation of macrophages, monocytes and the complement system $(31,32)$. Most components of the immune system participate in the pathogenesis of SLE, including elements of both the adaptive and innate immune response $(33,34)$. In autoimmune individuals, autoreactive cells are managed by the peripheral and central mechanisms of tolerance. MDSCs and Tregs serve important roles in the immunosuppressive networks. Tregs has been extensively studied in mouse models of lupus and in SLE patients $(35,36)$.

$\mathrm{CD}_{11} \mathrm{~b}^{+} \mathrm{Gr}-1^{\text {low }}$ cells have been identified in MRL-Fas ${ }^{l p r}$ mice, which develop a multi-organ inflammatory disorder that resembles human SLE (30). These cells increased in the blood and kidney during disease progression, and suppressed the proliferation of $\mathrm{CD}^{+} \mathrm{T}$ cells ex vivo. This suppression in proliferation can be blocked by the arginase-specific inhibitor Nor-NOHA, thus suggesting that arginase may be the principal element mediating suppression of MDSCs in MRL-Fas ${ }^{l p r}$ mice (37). In lupus-prone male F1 mice (strains NZB/NZW), Gr- $1^{\text {high }}$ Ly- $6 \mathrm{G}^{+} \mathrm{CD} 11 \mathrm{~b}^{+}$myeloid cells constitutively increased and were regulated by testosterone (38). These cells were located adjacent to spleen $B$ cell follicles and inhibit cytokine-induced differentiation of naïve $B$ cells into mature antibody-secreting B cells ex vivo. In addition, treatment with
anti-Gr-1-depleting antibodies can increase the spontaneous production of antinuclear antibodies (38). Furthermore, a study on an FcgR2b-knockout mouse model for SLE demonstrated that carbon monoxide administration inhibited the decline of Tregs, decreased the expansion of $\mathrm{CD}_{11} \mathrm{~b}^{+}$cells, decreased the antihistone antibodies and reduced kidney damage (39).

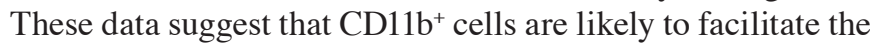
management of SLE, while the composition of these CD11b cells is not clearly understood.

\section{MDSCs and rheumatoid arthritis (RA)}

RA is a chronic inflammatory disease, which is characterized by the sequestration of various leukocyte subpopulations within the synovial space and developing pannus, resulting in the inflammation of multiple joints and the subsequent destruction of the joint cartilage and bone erosion (40-42). The role of MDSCs in autoimmune diseases remains controversial, and little is known about the function of MDSCs in RA.

Study of a collagen-induced arthritis (CIA) mouse model demonstrated that MDSCs serve crucial roles in the regulation of proinflammatory immune response (43). MDSCs were observed to have accumulated in the spleens of the mice when arthritis severity peaked. These MDSCs inhibited CD4 ${ }^{+}$ T cell proliferation and differentiation into Th17 cells ex vivo. Furthermore, the MDSCs inhibited the production of IL-2, IL-6, tumor necrosis factor (TNF) $-\alpha$ and IFN- $\gamma$ by CD4 ${ }^{+}$ T cells in vitro, whereas they promoted IL-10 production (43). Furthermore, adoptive transfer of MDSCs reduced the severity of CIA, and the number of Th17 and CD4 ${ }^{+}$T cells in the draining lymph nodes decreased. The depletion of MDSCs abrogated the improvement of CIA (43). These observations suggest that adoptive transfer of MDSCs can suppress the progression of CIA by inhibiting the proinflammatory immune response of $\mathrm{CD} 4^{+} \mathrm{T}$ cells. A study by Jiao et al (44) compared the frequency of circulating MDSCs and the plasma ARG-1 levels in RA patients and healthy controls. The results revealed that the frequency of circulating MDSCs and the plasma ARG-1 levels increased significantly in RA patients. However, no significant difference in iNOS at the mRNA level was observed between RA patients and healthy controls. The prevalence of Th17 cells in RA patients was higher when compared with that in healthy controls; however, Th17 cell frequency was negatively correlated with the percentage of MDSCs and the plasma ARG-1 levels. Furthermore, the study identified a negative correlation between MDSCs and plasma levels of TNF- $\alpha$. However, the MDSC percentage was not correlated with the plasma levels of IL-6 and IL-17, or with the RORgt mRNA expression (44). The study by Jiao et al revealed a negative correlation between circulating MDSCs and Th17 cells in RA patients, which may provide a new insight into the underlying mechanisms in RA. In a study by Zhang et al (45), MDSCs were isolated from the spleens of CIA mice and transferred to CIA mice via their tail vein, and then an arthritis model was established. The results demonstrated that adoptive transfer of MDSCs reduced the number of Th17 cells and macrophages in joint tissues, as well as downregulated the levels of IL-17, IL-6, IL-10 and TNF- $\alpha$ in the plasma and joints (45). Notably, the clinical score of arthritis, joint inflammation and histological damage were reduced (45). Another study indicated that synovial fluid in the 
joints of mice with proteoglycan-induced arthritis contained a population of G-MDSCs that potently suppressed $\mathrm{T}$ cell proliferation and DC maturation, and these MDSCs had the potential to control autoreactive $\mathrm{T}$ cell expansion (46).

All the aforementioned studies revealed that MDSCs serve crucial roles in the regulation of autoimmune arthritis, while the adoptive transfer of MDSCs can break the cycle of inflammation and autoimmunity, thus preventing autoimmune arthritis in mouse models of RA. These findings provide an insight into the inhibitory functions of MDSCs. These cells may be exploited as a novel cell-based biotherapy for human RA.

\section{MDSCs and experimental autoimmune myocarditis (EAM)}

Myocarditis, which describes a series of inflammatory disorders of the heart muscle with varied infectious and non-infectious origins, can lead to dilated cardiomyopathy in young patients. EAM is a mouse model of postinfectious myocarditis and represents a $\mathrm{CD}^{+} \mathrm{T}$ cell-mediated disease (47). Two major $\mathrm{CD} 4^{+} \mathrm{T}$ cell subsets have been previously defined according to their cytokine production pattern: IFN- $\gamma$-producing Th1 cells, and Th2 cells releasing IL-4. However, more recent data suggest that EAM development critically depends on the IL-23-STAT4 axis (48), promoting the expansion of another autoreactive $\mathrm{CD}^{+} \mathrm{T}$ cell subset characterized by IL-17 production (49). Immunosuppressive therapy is known to improve heart function in dilated cardiomyopathy patients with no evidence of bacterial or viral genomes in heart biopsies (50); however, the association of MDSCs and EAM remains largely unexplored. The only relevant study was conducted by Valaperti and colleagues (51), but did not investigate MDSC subsets directly. The authors identified that IL-17 promotes the recruitment of $\mathrm{CD}_{11} \mathrm{~b}^{+}$monocytes to the heart and the severity grading of myocarditis strongly depended on the extent of mononuclear infiltrates, including monocytes and macrophages $(52,53)$.

$\mathrm{CD}_{1} \mathrm{~b}^{+}$-expressing monocytes have been shown to be the major heart-infiltrating mononuclear cells at the peak of myocarditis. The CD11 $\mathrm{b}^{+}$monocytes found in the heart are not

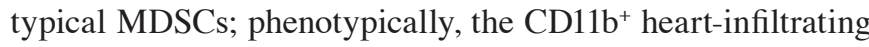
cells represent a heterogeneous population of largely immature F4/80, CD14, CD45 and CXCR4-positive monocytes, expressing low levels of MHC class II and Gr-1 (51). These findings are consistent with an early study by Liversidge et al (54) that used a mouse model of autoimmune uveoretinitis. The study showed the accumulation of NO-producing monocytes in the choroid and retina of the eye, which was correlated with the severity of disease. A later study by Kerr et al (55) observed similar results and confirmed the identity of those cells to be MDSCs.

Studies using the multiple sclerosis mouse model, EAE, revealed that MDSCs were present in the demyelinated areas of the spinal cord tissue of mice (56). This EAE model demonstrated that MDSC accumulation in the spleen correlated with disease progression (56). They identified that the $\mathrm{CD}_{11} \mathrm{~b}^{+}$monocytes are critical for an IFN- $\gamma$-dependent negative feedback loop that suppresses autoreactive $\mathrm{CD} 4^{+} \mathrm{T}$ cells and abrogates autoimmune myocarditis (51). It was concluded that the release of NO explains the suppressive effects of the

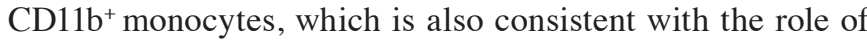
MDSCs observed in EAE (57). CD11b ${ }^{+}$monocytes mediate a disease limiting IFN- $\gamma$-triggered negative feedback loop, which suppresses heart-specific $\mathrm{T}$ cell responses (51). These data identified a disease-modulating role of $\mathrm{CD}_{11 \mathrm{~b}}{ }^{+}$, similar to other myeloid-derived cells reported in other autoimmune disease models $(2,58)$. Therefore, the present review speculates that MDSC proportions in the spleen and heart in EAM models may be significantly higher compared with that reported in EAE and other autoimmune models, while MDSC subsets can suppress Th17 activity and ameliorate disease severity in EAM. However, further studies are required to support these speculations. Although G-MDSCs and M-MDSCs are known to suppress $\mathrm{T}$ cell functions in other autoimmune disease models, further research is needed to confirm this suppressive activity in the EAM model. Our research group is currently focusing on the role of these Mregs in EAM, as well as the effect of HMGB1 on these Mregs in the pathogenesis of EAM disease.

\section{MDSCs and experimental autoimmune encephalo- myelitis (EAE)}

EAE is a commonly used mouse model of multiple sclerosis (59). Although EAE is considered to be a CD4-driven model, the effects of other cells playing a contributory role in EAE induction should not be discounted. Several studies have demonstrated the role of CD8 T cells during EAE (60-62), whereas others have indicated the importance of $\mathrm{B}$ cells and myeloid cells $(63,64)$. The induction of EAE has been observed to promote splenomegaly (referring to increased size of the spleen) due to increased influx of myeloid cells (65). Notably, granulocyte-macrophage colony-stimulating factor (GM-CSF) is a growth factor involved in the generation of MDSCs in the bone marrow, as well as the mobilization of cells from the bone marrow. This growth factor is required for the development of EAE, since GM-CSF-knockout mice are resistant to EAE and neutralization of GM-CSF attenuates EAE (66). This role of GM-CSF in EAE pathogenesis is speculated to be due to its ability to enhance TNF- $\alpha$-induced IL-6 (67) and the production of IL-23 (68), which are both mediators of Th17 cells, by DCs during the effector phase of EAE.

A recent study revealed that $\mathrm{CD} 11 \mathrm{~b}^{+} \mathrm{Ly} 6 \mathrm{C}^{+}$cells increased during the inflammatory phase of EAE and induced potent inhibition of $\mathrm{T}$ cell activation (69). In the EAE model, G-MDSCs from myelin oligodendrocyte glycoprotein-immunized mice were found to express high levels of programmed cell death 1 , ligand 1 (PD-L1), which is a co-stimulatory molecule that negatively regulates $\mathrm{T}$ cell proliferation (70). In addition, G-MDSCs were found to inhibit the autoantigen-priming of Th1 and Th17 cells in a PD-L1-dependent manner (70). Notably, a previous study demonstrated that CD11b $\mathrm{br}^{+} \mathrm{1}^{+}$cells isolated from mice with EAE inhibited $\mathrm{T}$ cell proliferation in co-culture with naive CD4 cells, but promoted Th17 cell differentiation under Th17-polarizing conditions (71). Another study demonstrated that activation of the suppressive function of M-MDSCs occurred at the peak of EAE disease (72). This aforementioned study determined that the suppression of T cell responses was due to M-MDSC-mediated NO production (72). 
Furthermore, transfer of activated M-MDSCs led to apoptosis of $\mathrm{T}$ cells in the central nervous system and decreased EAE severity.

\section{MDSC-mediated suppression of T-cell function}

MDSCs induce immune suppression by blocking $\mathrm{CD} 4^{+}$and $\mathrm{CD}^{+} \mathrm{T}$ cell activation, and the G-MDSCs and M-MDSCs can inhibit effector $\mathrm{T}$ cells by different modes of action (2). G-MDSCs are predominantly involved in immune suppression through the production of ROS, whereas the secretion of ARG-1 and generation of NO are mainly used by M-MDSCs (58). Peroxynitrite, which forms by the cooperative activity of ROS with $\mathrm{NO}$, is another factor that inhibits effector T cells (73). In addition, peroxynitrite leads to the nitration of tyrosines in the T-cell receptor (TCR)-CD8 complex. This reaction damages the conformational flexibility of the TCR-CD8 complex and affects its interaction with peptide-loaded MHC-I, leading to the unresponsiveness of $\mathrm{CD} 8^{+} \mathrm{T}$ cells to antigen-specific stimulation (74). Peroxynitrite can damage proteins in different processes in immune cells, including the regulation of MHC-II expression and T cell apoptosis $(2,17)$. MDSCs also directly downregulate $\mathrm{L}$-selectin on the surface of naïve $\mathrm{T}$ cells through the expression of a disintegrin and metalloproteinase domain 17, an enzyme that cleaves the ectodomain of L-selectin, decreasing its ability to migrate to sites where it can be activated, and thus reduces the number of $\mathrm{CD} 4^{+}$and $\mathrm{CD} 8^{+} \mathrm{T}$ cells (75). The suppressive activity of ARG-1 is based on its role in the hepatic urea cycle, metabolizing L-arginine to L-ornithine. ARG-1 expression has been reported to decrease $\mathrm{CD} 3 \xi$-chain biosynthesis, and to result in the downregulation of TCR on the cell surface (76). As a result, T cells are arrested in the G0-G1 phase of the cell cycle, which is associated with a deficiency of protein kinase complexes that serve an important role in G1 phase progression (77). In vitro, this phenomenon can be completely reversed by the replenishment of L-arginine (76). In vivo, the depletion of CD14 CD15 ${ }^{+}$G-MDSCs can reestablish the $\mathrm{CD} 3 \xi$-chain biosynthesis and $\mathrm{T}$ cell proliferation (77). The shortage of L-arginine also inhibits $\mathrm{T}$ cell proliferation by preventing upregulation of the expression of the cell cycle regulators, cyclin D3 and cyclin-dependent kinase 4 (76). NO suppresses the function of $\mathrm{T}$ cells involving the induction of $\mathrm{T}$ cell apoptosis (78), the inhibition of MHC-II expression (79), and the inhibition of JAK5 and STAT3 in T cells (80).

Tumor-expanded MDSCs induce anergy in NK cells via the membrane-bound transforming growth factor (TGF)- $\beta$, STAT5 and ARG-1, or through the NKp30 receptor $(81,82)$. MDSCs suppress NK cell cytotoxicity by inhibiting the production of NKG2D and IFN- $\gamma$ in models of glioma (83). In addition, IL-13 was shown to mediate its effect through the IL-4R-STAT6 pathway and to induce TGF- $\beta$-producing $\mathrm{CD}_{11} \mathrm{~b}^{+} \mathrm{Gr}-\mathrm{1}^{+}$MDSCs (84). This production of TGF- $\beta$, IL-13 and IL-4 impairs the functions of NK cells (85). Furthermore, MDSCs also inhibit macrophages through decreasing the production of IL-12, a tumor-promoting type 2 response (86).

\section{MDSCs and Th17 cells}

Th17 cells, characterized by the production of IL-17 and other pro-inflammatory cytokines, are identified in high frequencies in cancer patients and tumor-bearing animals $(87,88)$. Th17 cells have a defined role in the development of various types of autoimmune pathologies and inflammatory disorders. Blocking the function of IL-17 would significantly prevent the development of autoimmune disease. In a recent study, Th17 cells have been used as the drug target to treat autoimmune diseases $(89,90)$. Numerous researchers have investigated the association between Th17 cells and MDSCs, identifying the possibility of using Th17 cells as the target of MDSCs in the treatment of autoimmune diseases $(91,92)$.

A study by Chatterjee et al (93) demonstrated that MDSCs expanded in vitro or isolated from the tumor site were able to induce naïve $\mathrm{CD} 4^{+} \mathrm{T}$ cells to produce IL-17. In addition, the study found that MDSC-mediated induction of IL- $17^{+} \mathrm{T}$ cell response mainly depended on the cytokines secreted by MDSCs, rather than on the MDSC-T cell contact (93). NO is a common mediator of inflammation and immunity, which is involved in the pathogenesis of autoimmunity and infectious diseases. High concentrations of exogenous NO suppress the differentiation and proliferation of Th17 cells. However, a recent study by Obermajer et al (94) revealed that the expression of NOS2 positively correlated with the Th17 cell responses in patients with ovarian cancer. This finding suggests that the physiological NO concentrations produced by the MDSCs of cancer patients support the development of Th17 cells (94). In patients with gastrointestinal cancer, circulating MDSC levels were correlated with IL-17 production (95). A study by Jiao et al (95) determined the frequencies of Th17 cells and MDSCs in the peripheral blood of patients with esophageal cancer and healthy subjects by flow cytometry. The study results revealed that the frequencies of MDSCs and Th17 cells were markedly elevated in the esophageal cancer tissues of cancer patients compared with the healthy subjects; however, no correlation was observed between the frequencies of Th17 cells and MDSCs in the peripheral blood of patients (95). This observation will help to develop potential therapeutic strategies through prevention of the ability of MDSCs to induce the production of IL-17 by $\mathrm{CD}^{+} \mathrm{T}$ cells, and therefore inhibiting the generation of inflammatory Th17 population at the inflammatory disease site.

The differentiation of $\mathrm{CD}^{+} \mathrm{T}$ helper cells is essential for the development of robust immune responses to protect self-tissue. Previous findings suggest that different subsets of myeloid cells isolated from human peripheral blood regulate the developmental programs of TGF- $\beta$-dependent $\mathrm{CD}^{+} \mathrm{T}$ cells ex vivo (96). Human CD14 ${ }^{+} \mathrm{HLA}^{-D R^{-/ l o w}}$ MDSCs can induce Tregs, whereas CD14 ${ }^{+} \mathrm{HLA}-\mathrm{DR}^{+}$monocytes promote IL-17-secreting $\mathrm{RORc}^{+} \mathrm{Th} 17$ cell generation when co-cultured with naïve $\mathrm{CD}^{+} \mathrm{T}$ cells in vitro (97). Notably, MDSCs also promote the transdifferentiation of Tregs from CD14 ${ }^{+} \mathrm{HLA}^{-\mathrm{DR}^{+}}$monocyte-induced Th17 cells. This mechanism of the plasticity of human Th17 cells and induced Tregs (iTregs) is dependent on MDSC-derived retinoic acid and TGF- $\beta$ (96). Collectively, these findings indicate that different subsets of $\mathrm{CD}_{1} 4^{+}$myeloid cells may serve different role in the plasticity of $\mathrm{CD}^{+}{ }^{+} \mathrm{T}$ helper cells, which orchestrate the differentiation of naïve $\mathrm{CD} 4^{+} \mathrm{T}$ cells into the regulatory or effector $\mathrm{T}$ cell subsets. In addition, the balance between these two subsets can influence the outcome of immune response from tolerance to inflammation; therefore, different subsets of 
myeloid cells namely serve their own role in immune response regulation.

The study by Rieber et al (98) demonstrated that MDSC subsets with a neutrophilic or granulocytic phenotype isolated from the cord blood of neonatal infection patients were able to suppress IL-17 secretion. In the presence of an acute infection with the causative agent of Chagas disease (Trypanosma cruzi), C57BL/6 (B6) mice demonstrated increased inflammation and reduced survival compared with BALB/c mice. In addition, more G-MDSCs were identified in the livers and spleens of infected BALB/c mice compared with infected C57BL/6 (B6) mice. In vivo, the depletion of MDSCs led to a strong Th17 cell response with high parasitemia and mortality (6). These findings demonstrate that MDSCs can suppress Th17 response. In another study, MDSCs derived from patients infected with Pseudomonas aeruginosa evidently dampened the IL-17 protein production by $\mathrm{CD}^{+} \mathrm{T}$ cells and suppressed IL-17 protein expression in T cells (99). A previous T cell study demonstrated that the circulating percentages of neutrophilic MDSCs in graft over that in host disease patients treated with extracorporeal photopheresis increased rapidly (100). These cells efficiently dampened Th17 cell response, and this effect was positively correlated with the increase of cellular and extracellular arginase activity (100).

Considering the aforementioned studies, MDSCs and Thl7 cells serve important roles in autoimmune diseases. Therefore, understanding the association of these two cell types in the development of various autoimmune pathologies and inflammatory conditions is helpful to further understand the underlying mechanism of autoimmune diseases. The immune regulatory effects of MDSCs on Th17 cells provide novel ideas for the treatment of autoimmune diseases.

\section{MDSCs mediate Treg expansion}

Tregs are immunosuppressive T cells that exhibit potent inhibitory effects on effector $\mathrm{T}$ cells by producing inhibitory cytokines, killing effector cells by release of granzyme and perforin, interfering with the effector cell metabolism, and affecting Treg differentiation and proliferation by regulating the function of DCs (5). MDSCs and Tregs serve important roles in the immunosuppressive networks. The underlying mechanisms by which pathological conditions promote the expansion and/or function of these suppressive cells, as well as the crosstalk between MDSCs and Tregs, remain incompletely defined. Therefore, it is important to investigate the role of MDSCs in the attraction and activation of Tregs subsets, and the induction of iTregs.

Previous studies have demonstrated that MDSCs may promote the expansion of Tregs via TGF- $\beta$-dependent (101) and TGF- $\beta$-independent pathways (102). In tumor-bearing hosts, the induction of Tregs by MDSCs requires the presence of IL-10 and IFN- $\gamma$, and the activation of tumor-specific T cells; however, this is not dependent on the production of NO (98). In 1D8 ovarian tumor mice, the MDSC-mediated induction of Tregs required the expression of cytotoxic lymphocyte antigen 4 by MDSCs (103). A previous study revealed that

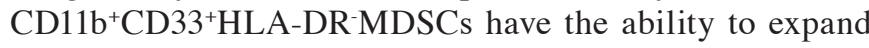
Tregs in vitro, and their accumulation following transplantation positively correlated with an increase in Tregs in vivo (104). In lymphoma mice, MDSCs promoted Treg expansion via a mechanism that involved ARG-1 and the capture, processing and presentation of tumor-associated antigens by MDSCs, but did not dependent of TGF- $\beta$ (99). In vitro, M-MDSCs isolated from skin tumor-bearing ret transgenic mice and from B16 melanoma expressed high levels of CCL5, and attracted high numbers of Tregs through CCR5 (105). In colon carcinoma mice, IFN- $\gamma$ activated $\mathrm{Gr}-1^{+} \mathrm{CD} 115^{+} \mathrm{M}-\mathrm{MDSCs}$ produce IL-10 and TGF- $\beta$, and upregulated MHC-II, mediating the development of tumor-induced Tregs. However, the Gr- $1^{+} \mathrm{CD} 115^{+} \mathrm{M}-\mathrm{MDSC}$ from CD40-deficient mice were unable to support tumor-specific Treg expansion, indicating the presence of CD40/CD40L interactions between the two cells (106). By contrast, another study has shown that the frequency of Tregs was high throughout tumor growth and was not associated with the expansion of the MDSC population, indicating that MDSCs were not involved in the induction of Tregs. In a kidney allograft tolerance rat model, induced via a CD28-specific antibody, it was observed that MDSCs had a finite number of effects on the expansion of the Treg population (73). This study provided evidence that tumor-induced G-MDSCs impair the TGF- $\beta 1$-mediated generation of iTregs. Furthermore, G-MDSCs impede the proliferation of natural Tregs without affecting FoxP3 expression. G-MDSCs also inhibit the differentiation of iTregs from naïve $\mathrm{CD}^{+}$cells, which occurs early in the polarization process. The inhibition of differentiation requires inhibition of early $\mathrm{T}$ cell activation, and depends on indoleamine 2,3-dioxigenase and ROS, but does not require ARG-1, iNOS, NO, PD-1 and PD-L1 signaling, or COX-2. These findings indicate that G-MDSCs from tumor-bearing hosts have the ability to restrict immunosuppressive Tregs (73). MDSCs and Tregs are important in limiting autoimmune diseases, and immune regulation of Tregs by MDSCs provides potential for the treatment of autoimmune diseases through the application of MDSCs.

\section{Therapeutic potential of MDSCs in autoimmune disorders}

Considering the variety of functions reported for MDSCs in autoimmune disorders, determining a unifying hypothesis to explain their role(s) in autoimmune disease is challenging. However, the information accumulated in recent years confirms that MDSCs serves a critical role in the regulatory component of autoimmune inflammatory environments. In order to develop effective MDSC-based therapies, it is essential to first understand how different cell types respond to different inflammatory mediators, as well as to determine how these inflammatory mediators affect the potency and/or suppressive mechanisms of MDSCs. Various studies have shown promising outcomes (107), with few unsuccessful findings reported (46). $\mathrm{CD}_{11 \mathrm{~b}} \mathrm{Gr}^{+} 1^{+}$cells isolated from mice with autoimmune disorder appear to have the ability to inhibit T cell response ex vivo. In vivo, these endogenous $\mathrm{CD} 11 \mathrm{~b}^{+} \mathrm{Gr}-1^{+}$ cells appear to be rather ineffective at preventing autoimmune disease, and may even exacerbate disease $(46,108)$. By contrast, the adoptive transfer of exogenously MDSCs has been proven to prevent autoimmune pathologies in mice models of RA (45), type 1 diabetes (109), alopecia areata (110) and inflammatory bowel disease (111). A study by Ioannou et al (91) observed that the in vivo transfer of G-MDSCs in the EAE model 
resulted in the delayed onset of disease and in a significant reduction in demyelination. It has also been found that adoptive transfer of MDSCs also led to reduced disease severity in models of RA $(43,112)$.

The difference between the function of exogenously-applied and endogenous MDSCs recruited to an autoimmune site may be caused by the difference in activity between these two MDSC populations. In addition, certain factors within the autoimmune inflammatory environments may prevent MDSCs from exerting their suppressive potential (20,30,113-116). Research in the field of MDSC biology in autoimmune inflammatory has yielded more questions than answers. MDSCs, as regulatory components of the immune system subsets, have specific roles in mediating effector $\mathrm{T}$ cell suppression and Treg expansion, suggesting that exogenously applied MDSCs may be an attractive opportunity by which to inhibit immune responses in the autoimmune disorders. Studies have demonstrated that MDSCs can be expanded through numerous ways ex vivo $(117,118)$, stored for long periods of time in liquid nitrogen and readministered. However, potential risks associated with utilizing MDSCs to limit autoimmune disorders must be estimated. Functionally suppressive MDSCs may serve a beneficial role in systemic autoimmune disorders, by promoting the Treg expansion and inhibiting effector $\mathrm{T}$ cell-mediated inflammation and pathology, although there are numerous questions remaining to be solved.

Various research groups have demonstrated the possibility of using MDSC-based therapies in the treatment of autoimmune diseases $(24,119,120)$. A primary concern has been raised that needs to be resolved prior to the use of these MDSC-based therapies in the treatment of autoimmune diseases. It is known that these MDSCs are not terminally differentiated and can mature into inflammatory antigen-presenting cells, such as dendritic cells and macrophages, under inflammatory disease conditions. These inflammatory cells may then exacerbate the inflammatory disease that they are used to treat (121-123), which highlights a potential complication in therapeutic attempts. Recently, a much larger group of cells, known as the regulatory myeloid cells, have been identified that encompass MDSCs, and their roles may add up to the envisaged problems that may affect the success of using the MDSC-based therapies to treat autoimmune diseases.

\section{Myeloid regulatory-mediated activation of $T$ cell func- tion in cancer and autoimmune models}

Mregs, as shown in Fig. 1, include MDSCs, regulatory DCs, regulatory macrophages, and subsets of granulocytes that expand during pathologic conditions and have the ability to suppress cellular immunity (124). Notably, these Mregs have recently attracted certain research attention, particularly due to their roles in cancer and autoimmune diseases. MDSCs reflect a mechanism by which these Mregs suppress the host's anti-tumor immune responses in favor of the tumors. They are known to be harmful to anti-tumor immunity, in which Th1 or CTL responses are required, as shown in Fig. 2. Mregs, including MDSCs, conventional DCs, lung-resident tissue macrophages, monocytes and plasmacytoid DCs, have been shown to impact the disease course in animal models of diabetes (108), colitis (125), allergic asthma (126), experimental autoimmune disease (127) and RA (128), respectively. Suppression of the Th1 and CTL responses is known to promote cancer progression. Immunoregulatory functions of Mregs on Th17 differentiation and inflammatory responses have been reported in EAE (90). It has been observed that the progression of EAE in mice was accompanied by a profound expansion of $\mathrm{CD} 11 \mathrm{~b}^{+} \mathrm{Gr}-1^{+}$MDSCs, which phenotypically and functionally resembled tumor-expanded MDSCs (90). However, these EAE-associated Mregs were found to be highly efficient in producing IL- $1 \beta$, thereby promoting the differentiation of naïve CD4 into Th17 cells. Increasing Th17 cells have been identified to be responsible for the increased severity in a number of autoimmune diseases. Another study group depleted the level of Mregs in EAE disease using gemcitabine, and a marked reduction in the severity of EAE was observed, along with decreased levels of Th17 cells and their inflammatory cytokines, IL-17A and IL-1 $\beta$, in the lymphoid tissues and spinal cord of their subjects (90). The pathogenic activities of CCR2 $2^{+} \mathrm{Ly} 6 \mathrm{C}^{\text {high }}$ or $\mathrm{CD} 11 \mathrm{~b}^{+} \mathrm{Ly} 6 \mathrm{C}^{\text {high }}$ cells, which are likely due to monocytic Mregs, have also been reported in two studies $(46,107)$. The ability of Mregs to induce Th17 differentiation has also been demonstrated in tumor-bearing mice (92) and patients with ovarian cancer (92). Development of Th17 cells from naïve-, memory-, or tumor-infiltrating CD4 cells has been shown to be driven by Mregs that produce IL-1 $\beta$, IL-6, IL-23 and NO (81). Indeed, recent studies also supported a positive correlation of Mregs levels with the levels of Th17 cells or IL-17 production in patients with esophageal cancer (92) or gastrointestinal cancer (129). Similarly, a decrease in MRC population and/or activity has been observed to have positive immune-potentiating effects. Several clinical trials have thus been initiated with the goal of manipulating the expansion or activation of these cells, and thereby improving patient immune responses (124). Therefore, the therapeutic benefits of targeting Mregs in autoimmune disorders have been proposed and remain to be clarified.

\section{Conclusion}

Mregs may function in the exacerbation and amelioration of different diseases associated with the suppression or induction of specific cytokines associated with the immune response. Specifically, MDSCs can induce Th17 response, thereby promoting the severity of various autoimmune diseases, as well as promoting cancer progression. These cells are known to also display particular heterogeneity and plasticity, and have thus become an attractive candidate for the treatment of autoimmune diseases. However, it is speculated that the harmful role of MDSCs and Mregs in autoimmune diseases and various types of cancer outweighs the benefits, despite certain promising data in using these cells for therapeutic purposes, particularly in the treatment of systemic autoimmune diseases.

\section{Acknowledgements}

The present study was supported by the National Natural Science Foundation of China (grant nos. 81370084, 31270947, 81001319 and 81101677), the Postdoctoral Foundation of China (grant nos. 2012M511705 and 2013T60508), and the Postdoctoral Foundation of Jiangsu province (grant no. 1102129C). 


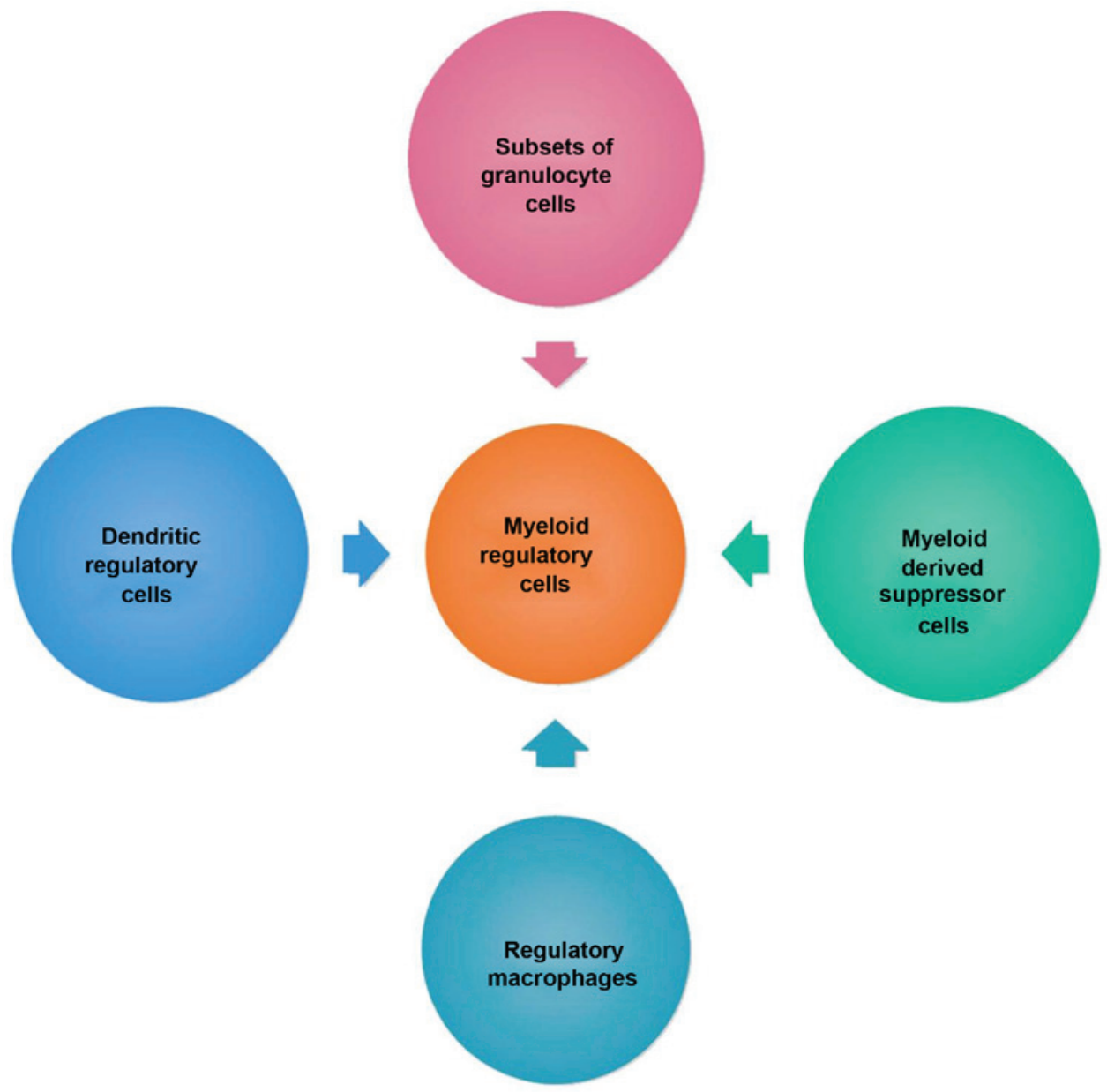

Figure 1. Constituents of myeloid regulatory cells.

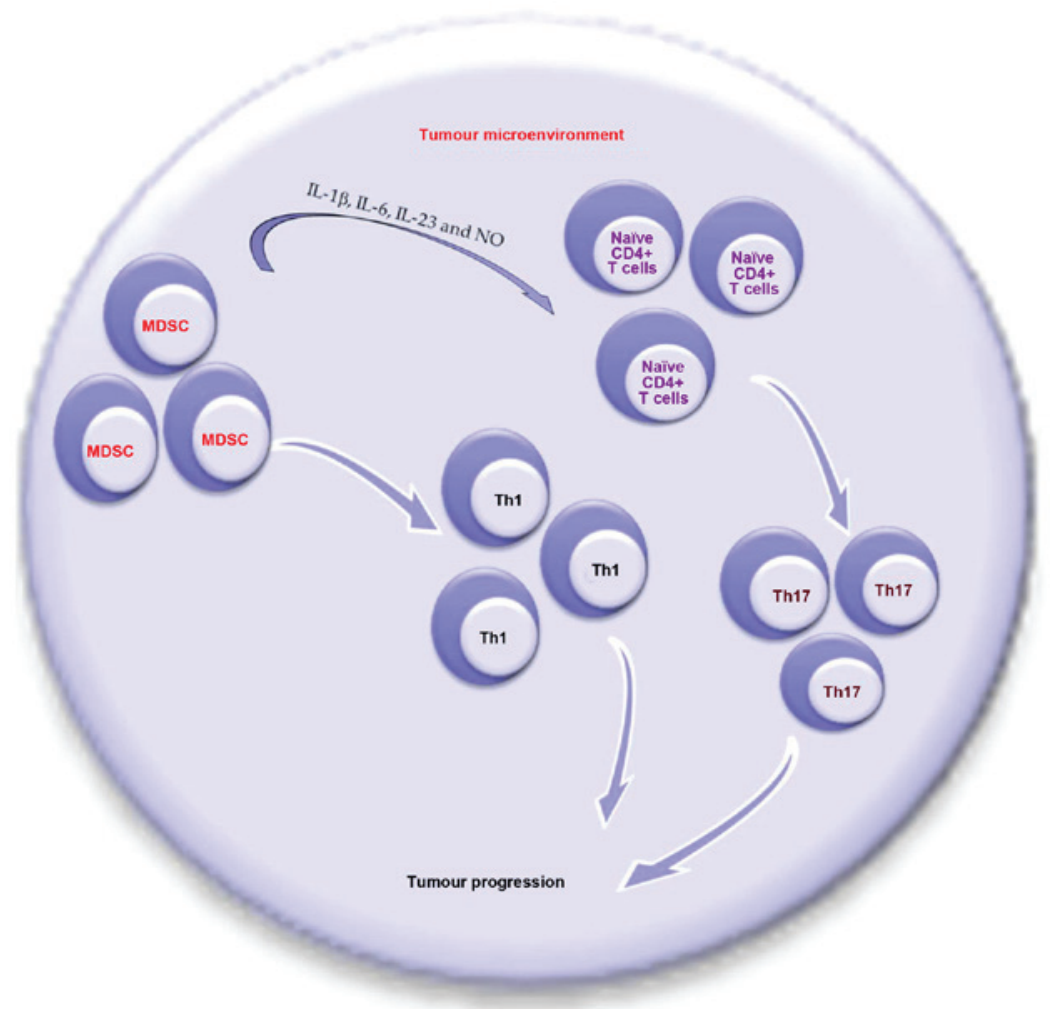

Figure 2. Pathologic function of myeloid-derived suppressor cells in tumour microenvironment. Th, Thelper cells; MDSC, myeloid-derived suppressor cell; IL, interleukin; NO, nitric oxide. 


\section{References}

1. Nicholson LB, Raveney BJ and Munder M: Monocyte dependent regulation of autoimmune inflammation. Curr Mol Med 9: 23-29, 2009.

2. Gabrilovich DI and Nagaraj S: Myeloid-derived suppressor cells as regulators of the immune system. Nat Rev Immunol 9: 162-174, 2009.

3. Bunt SK, Yang L, Sinha P, Clements VK, Leips J and Ostrand-Rosenberg S: Reduced inflammation in the tumor microenvironment delays the accumulation of myeloid-derived suppressor cells and limits tumor progression. Cancer Res 67 10019-10026, 2007.

4. Huang YH,Zozulya AL, Weidenfeller C, Schwab N and Wiendl H: T cell suppression by naturally occurring HLA-G-expressing regulatory $\mathrm{CD}^{+} \mathrm{T}$ cells is IL-10-dependent and reversible. J Leukoc Biol 86: 273-281, 2009.

5. Grossman WJ, Verbsky JW, Tollefsen BL, Kemper C, Atkinson JP and Ley TJ: Differential expression of granzymes A and B in human cytotoxic lymphocyte subsets and $\mathrm{T}$ regulatory cells Blood 104: 2840-2848, 2004.

6. Arocena AR, Onofrio LI,Pellegrini AV, Carrera Silva AE, Paroli A, Cano RC, Aoki MP and Gea S: Myeloid-derived suppressor cells are key players in the resolution of inflammation during a model of acute infection. Eur J Immunol 44: 184-194, 2014.

7. Sunhwa K and Karin M: Role of TLR2-dependent inflammation in metastatic progression. Ann NY Acad Sci 1217: 191-206, 2011.

8. Manjili MH, Wang XY and Abrams S: Evolution of our understanding of myeloid regulatory cells: From MDSCs to Mregs. Front Immunol 5: 303, 2014.

9. Youn JI, Nagaraj S, Collazo M and Gabrilovich DI: Subsets of myeloid-derived suppressor cells in tumor-bearing mice. J Immunol 181: 5791-5802, 2008.

10. Zhu B, Bando Y, Xiao S, Yang K, Anderson AC, Kuchroo VK and Khoury SJ: CD $11 b^{+} L y-6 C^{\text {hi }}$ suppressive monocytes in experimental autoimmune encephalomyelitis. J Immunol 179 5228-5237, 2007

11. Dietlin TA, Hofman FM, Lund BT, Gilmore W, Stohlman SA and van der Veen RC: Mycobacteria-induced $\mathrm{Gr}-1^{+}$subsets from distinct myeloid lineages have opposite effects on $\mathrm{T}$ cell expansion. J Leukoc Biol 81: 1205-1212, 2007.

12. Hettinger J, Richards DM, Hansson J, Barra MM, Joschko AC, Krijgsveld $\mathrm{J}$ and Feuerer M: Origin of monocytes and macrophages in a committed progenitor. Nat Immunol 14: 821-830, 2013.

13. Almand B, Clark JI, Nikitina E, van Beynen J, English NR, Knight SC, Carbone DP and Gabrilovich DI: Increased production of immature myeloid cells in cancer patients: A mechanism of immunosuppression in cancer. J Immunol 166: 678-689, 2001.

14. Srivastava MK, Andersson $\AA$, Zhu L, Harris-White M, Lee JM, Dubinett $S$ and Sharma S: Myeloid suppressor cells and immune modulation in lung cancer. Immunotherapy 4: 291-304, 2012.

15. Talmadge JE and Gabrilovich DI: History of myeloid-derived suppressor cells. Nat Rev Cancer 13: 739-752, 2013.

16. Vasievich EA and Huang L: The suppressive tumor microenvironment: A challenge in cancer immunotherapy. Mol Pharm 8 : 635-641, 2011.

17. Gabrilovich DI, Ostrand-Rosenberg S and Bronte V: Coordinated regulation of myeloid cells by tumours. Nat Rev Immunol 12 : 253-268, 2012

18. Auffray C, Sieweke MH and Geissmann F: Blood monocytes: Development, heterogeneity, and relationship with dendritic cells. Annu Rev Immunol 27: 669-692, 2009.

19. Peranzoni E, Zilio S, Marigo I, Dolcetti L, Zanovello P, Mandruzzato S and Bronte V: Myeloid-derived suppressor cell heterogeneity and subset definition. Curr Opin Immunol 22: $238-244,2010$

20. Marigo I, Bosio E, Solito S, Mesa C, Fernandez A, Dolcetti L, Ugel S, Sonda N, Bicciato S, Falisi E, et al: Tumor-induced tolerance and immune suppression depend on the C/EBPbeta transcription factor. Immunity 32: 790-802, 2010

21. Condamine T and Gabrilovich DI: Molecular mechanisms regulating myeloid-derived suppressor cell differentiation and function. Trends Immunol 32: 19-25, 2011.

22. Zhang H, Nguyen-Jackson H, Panopoulos AD, Li HS, Murray PJ and Watowich SS: STAT3 controls myeloid progenitor growth during emergency granulopoiesis. Blood 116: 2462-2471, 2010.

23. Cain DW, Snowden PB, Sempowski GD and Kelsoe G: Inflammation triggers emergency granulopoiesis through a density-dependent feedback mechanism. PLoS One 6: e19957, 2011.
24. Youn JI and Gabrilovich DI: The biology of myeloid-derived suppressor cells: The blessing and the curse of morphological and functional heterogeneity. Eur J Immunol 40: 2969-2975, 2010.

25. Vesely MD, Kershaw MH, Schreiber RD and Smyth MJ: Natural innate and adaptive immunity to cancer. Annu Rev Immunol 29: 235-271, 2011.

26. Lechner MG, Megiel C, Russell SM, Bingham B, Arger N, Woo T and Epstein AL: Functional characterization of human $\mathrm{Cd}_{3} 3^{+}$and $\mathrm{Cd}_{11 \mathrm{~b}^{+}}$myeloid-derived suppressor cell subsets induced from peripheral blood mononuclear cells co-cultured with a diverse set of human tumor cell lines. J Transl Med 9: 90, 2011.

27. Filipazzi P, Valenti R, Huber V, Pilla L, Canese P, Iero M, Castelli C, Mariani L, Parmiani G and Rivoltini L: Identification of a new subset of myeloid suppressor cells in peripheral blood of melanoma patients with modulation by a granulocyte-macrophage colony-stimulation factor-based antitumor vaccine. J Clin Oncol 25: 2546-2553, 2007.

28. Poschke I, Mougiakakos D, Hansson J, Masucci GV and Kiessling R: Immature immunosuppressive CD14 ${ }^{+} \mathrm{HLA}_{-} \mathrm{DR}^{-/ \mathrm{low}}$ cells in melanoma patients are Stat3hi and overexpress CD80, CD83, and DC-sign. Cancer Res 70: 4335-4345, 2010.

29. Serafini P, Meckel K, Kelso M, Noonan K, Califano J, Koch W, Dolcetti L, Bronte V and Borrello I: Phosphodiesterase-5 inhibition augments endogenous antitumor immunity by reducing myeloid-derived suppressor cell function. J Exp Med 203: 2691-2702, 2006

30. Cripps JG and Gorham JD: MDSC in autoimmunity. Int Immunopharmacol 11: 789-793, 2011.

31. Brown EE, Edberg JC and Kimberly RP: Fc receptor genes and the systemic lupus erythematosus diathesis. Autoimmunity 40: 567-581, 2007.

32. Cohen PL: T-and B-cell abnormalities in systemic lupus. J Invest Dermatol 100 (Suppl): 69S-72S, 1993.

33. Crispín JC, Kyttaris VC, Terhorst C and Tsokos GC: T cells as therapeutic targets in SLE. Nat Rev Rheumatol 6: 317-325, 2010.

34. Sanz I and Lee FE: B cells as therapeutic targets in SLE. Nat Rev Rheumatol 6: 326-337, 2010.

35. Scheinecker C, Bonelli M and Smolen JS: Pathogenetic aspects of systemic lupus erythematosus with an emphasis on regulatory T cells. J Autoimmun 35: 269-275, 2010.

36. Chavele KM and Ehrenstein MR: Regulatory T-cells in systemic lupus erythematosus and rheumatoid arthritis. FEBS Lett 585 3603-3610, 2011.

37. Iwata Y, Furuichi K, Kitagawa K, Hara A, Okumura T, Kokubo S, Shimizu K, Sakai N, Sagara A, Kurokawa Y, et al: Involvement of CD $11 b^{+}$GR- $1^{\text {low }}$ cells in autoimmune disorder in MRL-Fas ${ }^{l p r}$ mouse Clin Exp Nephrol 14: 411-417, 2010.

38. Trigunaite A, Khan A, Der E, Song A, Varikuti S and Jørgensen TN: $\mathrm{Gr}-1^{\text {high }} \mathrm{CD} 1 \mathrm{Bb}^{+}$cells suppress B cell differentiation and lupus-like disease in lupus-prone male mice. Arthritis Rheum 65: 2392-2402, 2013.

39. Mackern-Oberti JP, Llanos C, Carreño LJ, Riquelme SA, Jacobelli SH, Anegon I and Kalergis AM: Carbon monoxide exposure improves immune function in lupus-prone mice. Immunology 140: 123-132, 2013

40. Kasama T, Strieter RM, Lukacs NW, Lincoln PM, Burdick MD and Kunkel SL: Interleukin-10 expression and chemokine regulation during the evolution of murine type II collagen-induced arthritis. J Clin Invest 95: 2868, 1995

41. Cuzzocrea S:. Shock, inflammation and PARP. Pharmacol Res 52:72-82, 2005.

42. Cuzzocrea S, Mazzon E, Di Paola R, Muià C, Crisafulli C, Dugo L, Collin M, Britti D, Caputi AP and Thiemermann C: Glycogen synthase kinase- $3 \beta$ inhibition attenuates the degree of arthritis caused by type II collagen in the mouse. Clin Immunol 120, 57-67, 2006.

43. Fujii W, Ashihara E, Hirai H, Nagahara H, Kajitani N, Fujioka K, Murakami K, Seno T, Yamamoto A, Ishino H, et al: Myeloid-derived suppressor cells play crucial roles in the regulation of mouse collagen-induced arthritis. J Immunol 191: 1073-1081, 2013.

44. Jiao Z, Hua S, Wang W, Wang H, Gao J and Wang X: Increased circulating myeloid-derived suppressor cells correlated negatively with Th17 cells in patients with rheumatoid arthritis. Scand J Rheumatol 42: 85-90, 2013

45. Zhang L, Zhang Z, Zhang H, Wu M and Wang Y: Myeloid-derived suppressor cells protect mouse models from autoimmune arthritis via controlling inflammatory response. Inflammation 37: 670-677, 2014

46. King IL, Dickendesher TL and Segal BM: Circulating Ly-6C ${ }^{+}$ myeloid precursors migrate to the CNS and play a pathogenic role during autoimmune demyelinating disease. Blood 113: 3190-3197, 2009. 
47. Souders CA, Bowers SL and Baudino TA: Cardiac fibroblast: The renaissance cell. Circ Res 105: 1164-1176, 2009.

48. Männer J, Pérez-Pomares JM, Macias D and Muñoz-Chápuli R: The origin, formation and developmental significance of the epicardium: A review. Cells Tissues Organs 169: 89-103, 2001.

49. Norris RA, Borg TK, Butcher JT, Baudino TA, Banerjee I and Markwald RR: Neonatal and adult cardiovascular pathophysiological remodeling and repair: developmental role of periostin. Ann N Y Acad Sci 1123: 30-40, 2008.

50. Kakkar R and Lee RT: Intramyocardial fibroblast myocyte communication. Circ Res 106: 47-57, 2010.

51. Valaperti A, Marty RR, Kania G, Germano D, Mauermann N, Dirnhofer S, Leimenstoll B, Blyszczuk P, Dong C, Mueller C, et al: $\mathrm{CD}_{11 b^{+}}$monocytes abrogate $\mathrm{Th} 17 \mathrm{CD} 4^{+} \mathrm{T}$ cell-mediated experimental autoimmune myocarditis. J Immunol 180: 2686-2695, 2008

52. Calabrese F, Angelini A, Carturan E and Thiene G: Myocarditis and inflammatory cardiomyopathy: Histomorphological diagnosis. Ernst Schering Res Found Workshop 305-321, 2006

53. Calabrese F and Thiene G: Myocarditis and inflammatory cardiomyopathy: Microbiological and molecular biological aspects. Cardiovasc Res 60: 11-25, 2003

54. Liversidge J, Dick A and Gordon S: Nitric oxide mediates apoptosis through formation of peroxynitrite and Fas/Fas-ligand interactions in experimental autoimmune uveitis. Am J Pathol 160: 905-916, 2002.

55. Kerr EC, Raveney BJ, Copland DA, Dick AD and Nicholson LB Analysis of retinal cellular infiltrate in experimental autoimmune uveoretinitis reveals multiple regulatory cell populations. J Autoimmun 31: 354-361, 2008

56. Moliné-Velázquez V, Cuervo $\mathrm{H}$, Vila-del Sol V, Ortega MC, Clemente D and de Castro F: Myeloid-derived suppressor cells limit the inflammation by promoting T lymphocyte apoptosis in the spinal cord of a murine model of multiple sclerosis. Brain Pathol 21: 678-691, 2011.

57. Zhu B, Kennedy JK, Wang Y, Sandoval-Garcia C, Cao L, Xiao S Wu C, Elyaman W and Khoury SJ: Plasticity of Ly-6C(hi) myeloid cells in T cell regulation. J Immunol 187: 2418-2432, 2011.

58. Movahedi K, Guilliams M, Van den Bossche J, Van den Bergh R, Gysemans C, Beschin A, De Baetselier P and Van Ginderachter JA: Identification of discrete tumor-induced myeloid-derived suppressor cell subpopulations with distinct T cell-suppressive activity. Blood 111: 4233-4244, 2008.

59. Raine CS: Biology of disease. Analysis of autoimmune demyelination: Its impact upon multiple sclerosis. Lab Invest 50: 608-635, 1984.

60. Ford ML and Evavold BD: Specificity, magnitude, and kinetics of MOG-specific $\mathrm{CD} 8^{+} \mathrm{T}$ cell responses during experimental autoimmune encephalomyelitis. Eur J Immunol 35: 76-85, 2005.

61. Sun D, Whitaker JN, Huang Z, Liu D, Coleclough C, Wekerle H and Raine CS: Myelin antigen-specific $\mathrm{CD} 8^{+} \mathrm{T}$ cells are encephalitogenic and produce severe disease in C57BL/6 mice. J Immunol 166 : 7579-7587, 2001

62. Sun D, Zhang Y, Wei B, Peiper SC, Shao H and Kaplan HJ: Encephalitogenic activity of truncated myelin oligodendrocyte glycoprotein $(\mathrm{MOG})$ peptides and their recognition by $\mathrm{CD} 8^{+}$ MOG-specific T cells on oligomeric MHC class I molecules. Int Immunol 15: 261-268, 2003.

63. McFarland HF and Martin R: Multiple sclerosis: a complicated picture of autoimmunity. Nature Immunol 8: 913-919, 2007.

64. Nauta AJ and Fibbe WE: Immunomodulatory properties of mesenchymal stromal cells. Blood 110: 3499-3506, 2007.

65. Billiau A and Matthys P: Modes of action of Freund's adjuvants in experimental models of autoimmune diseases. J Leukoc Biol 70 849-860, 2001

66. Roncarolo MG and Gregori S: Is FOXP3 a bona fide marker for human regulatory T cells? Eur J Immunol 38: 925-927, 2008.

67. Brissette WH, Baker DA, Stam EJ, Umland JP and Griffiths RJ: GM-CSF rapidly primes mice for enhanced cytokine production in response to LPS and TNF. Cytokine 7: 291-295, 1995.

68. Sonderegger I, Iezzi G, Maier R, Schmitz N, Kurrer M and Kopf M: GM-CSF mediates autoimmunity by enhancing IL-6-dependent Th17 cell development and survival. J Exp Med 205: 2281-2294 2008 .

69. Saiwai H, Kumamaru H, Ohkawa Y, Kubota K, Kobayakawa K, Yamada H, Yokomizo T, Iwamoto Y and Okada S: Ly6C ${ }^{+}$Ly6GMyeloid-derived suppressor cells play a critical role in the resolution of acute inflammation and the subsequent tissue repair process after spinal cord injury. J Neurochem 125: 74-88, 2013.

70. Ostrand-Rosenberg S and Sinha P: Myeloid-derived suppressor cells: Linking inflammation and cancer. J Immunol 182: 4499-4506, 2009.
71. Yang L, Huang J, Ren X, Gorska AE, Chytil A, Aakre M, Carbone DP, Matrisian LM, Richmond A, Lin PC and Moses HL: Abrogation of TGF beta signaling in mammary carcinomas recruits $\mathrm{Gr}-1^{+} \mathrm{CD} 11 \mathrm{~b}^{+}$myeloid cells that promote metastasis Cancer Cell 13: 23-35, 2008

72. Fichtner-Feigl S, Terabe M, Kitani A, Young CA, Fuss I, Geissler EK, Schlitt HJ, Berzofsky JA and Strober W: Restoration of tumor immunosurveillance via targeting of interleukin-13 receptor-alpha2. Cancer Res 68: 3467-3475, 2008.

73. Kusmartsev S, Nefedova Y, Yoder D and Gabrilovich DI: Antigen-specific inhibition of $\mathrm{CD} 8^{+} \mathrm{T}$ cell response by immature myeloid cells in cancer is mediated by reactive oxygen species. J Immunol 172: 989-999, 2004.

74. Nagaraj S, Gupta K, Pisarev V, Kinarsky L, Sherman S, Kang L, Herber DL, Schneck J and Gabrilovich DI: Altered recognition of antigen is a mechanism of $\mathrm{CD}^{+} \mathrm{T}$ cell tolerance in cancer. Nat Med 13: 828-835, 2007.

75. Hanson EM, Clements VK, Sinha P, Ilkovitch D and Ostrand-Rosenberg S: Myeloid-derived suppressor cells down-regulate $\mathrm{L}$-selectin expression on $\mathrm{CD}^{+}$and $\mathrm{CD} 8^{+} \mathrm{T}$ cells. J Immunol 183: 937-944, 2009.

76. Rodriguez PC, Quiceno DG and Ochoa AC: L-arginine availability regulates T-lymphocyte cell-cycle progression. Blood 109: 1568-1573, 2007.

77. Zea AH, Rodriguez PC, Atkins MB, Hernandez C, Signoretti S, Zabaleta J, McDermott D, Quiceno D, Youmans A, O'Neill A, et al: Arginase-producing myeloid suppressor cells in renal cell carcinoma patients: A mechanism of tumor evasion. Cancer Res 65: 3044-3048, 2005.

78. Rivoltini L, Carrabba M, Huber V, Castelli C, Novellino L, Dalerba P, Mortarini R, Arancia G, Anichini A, Fais S and Parmiani G: Immunity to cancer: Attack and escape in T lymphocyte-tumor cell interaction. Immunol Rev 188: 97-113, 2002.

79. Harari O and Liao JK: Inhibition of MHC II gene transcription by nitric oxide and antioxidants. Curr Pharm Des 10: 893-898, 2004

80. Bingisser RM, Tilbrook PA, Holt PG and Kees UR: Macrophage-derived nitric oxide regulates $\mathrm{T}$ cell activation via reversible disruption of the Jak3/STAT5 signaling pathway. J Immunol 160: 5729-5734, 1998

81. Hoechst B, Voigtlaender T, Ormandy L, Gamrekelashvili J, Zhao F, Wedemeyer H, Lehner F, Manns MP, Greten TF and Korangy F: Myeloid derived suppressor cells inhibit natural killer cells in patients with hepatocellular carcinoma via the NKp30 receptor. Hepatology 50: 799-807, 2009.

82. Oberlies J, Watzl C, Giese T, Luckner C, Kropf P, Müller I, Ho AD and Munder M: Regulation of NK cell function by human granulocyte arginase. J Immunol 182: 5259-5267, 2009.

83. Alizadeh D, Zhang L, Brown CE, Farrukh O, Jensen MC and Badie B: Induction of anti-glioma natural killer cell response following multiple low-dose intracerebral $\mathrm{CpG}$ therapy. Clin Cancer Res 16: 3399-3408, 2010.

84. Terabe M, Matsui S, Noben-Trauth N, Chen H, Watson C, Donaldson DD, Carbone DP, Paul WE and Berzofsky JA: NKT cell-mediated repression of tumor immunosurveillance by IL-13 and the IL-4R-STAT6 pathway. Nat Immunol 1: 515-520, 2000.

85. Crane CA, Han SJ, Barry JJ, Ahn BJ, Lanier LL and Parsa AT: TGF-beta downregulates the activating receptor NKG2D on NK cells and $\mathrm{CD}^{+} \mathrm{T}$ cells in glioma patients. Neuro Oncol 12: 7-13, 2010.

86. Sinha P, Clements VK, Bunt SK, Albelda SM and Ostrand-Rosenberg S: Cross-talk between myeloid-derived suppressor cells and macrophages subverts tumor immunity toward a type 2 response. J Immunol 179: 977-983, 2007

87. Jandus C, Bioley G, Rivals JP, Dudler J, Speiser D and Romero P: Increased numbers of circulating polyfunctional Th17 memory cells in patients with seronegative spondylarthritides. Arthritis Rheumatism 58: 2307-2317, 2008

88. Muranski P, Boni A, Antony PA, Cassard L, Irvine KR, Kaiser A Paulos CM, Palmer DC, Touloukian CE, Ptak K and Gattinoni L: Tumor-specific Th17-polarized cells eradicate large established melanoma. Blood 12: 362-373, 2008

89. Viola A and Luster AD: Chemokines and their receptors: drug targets in immunity and inflammation. Annu Rev Pharmacol Toxicol 48: 171-197, 2008.

90. Wong CK, Lit LXW, Tam LS, Li EKM, Wong PTY and Lam CWK: Hyperproduction of IL-23 and IL-17 in patients with systemic lupus erythematosus: implications for Th17-mediated inflammation in auto-immunity. Clinical Immunol 127: 385-393 (2008). 
91. Ioannou M, Alissafi T, Lazaridis I, Deraos G, Matsoukas J, Gravanis A, Mastorodemos V, Plaitakis A, Sharpe A, Boumpas D and Verginis P: Crucial role of granulocytic myeloid-derived suppressor cells in the regulation of central nervous system autoimmune disease. J Immunol 188: 1136-1146, 2012.

92. Yi H, Guo C, Yu X, Zuo D and Wang XY: Mouse CD11b ${ }^{+} \mathrm{Gr}-1^{+}$ myeloid cells can promote Th17 cell differentiation and experimental autoimmune encephalomyelitis. J Immunol 189: 4295-4304, 2012.

93. Chatterjee S, Das S, Chakraborty P, Manna A, Chatterjee M and Choudhuri SK: Myeloid derived suppressor cells (MDSCs) can induce the generation of Th17 response from naive $\mathrm{CD} 4^{+} \mathrm{T}$ cells. Immunobiology 218: 718-724, 2013.

94. Obermajer N, Wong JL, Edwards RP, Chen K, Scott M, Khader S, Kolls JK, Odunsi K, Billiar TR and Kalinski P: Induction and stability of human Th17 cells require endogenous NOS2 and cGMP-dependent NO signaling. J Exp Med 210: 1433-1445, 2013.

95. Jiao ZJ, Gao JJ, Hua SH, Chen DY, Wang WH, Wang H, Wang XH and $\mathrm{Xu} \mathrm{HX}$ : Correlation between circulating myeloid-derived suppressor cells and Th17 cells in esophageal cancer. World J Gastroenterol 18: 5454-5461, 2012.

96. Hoechst B, Gamrekelashvili J, Manns MP, Greten TF and Korangy F: Plasticity of human Th17 cells and iTregs is orchestrated by different subsets of myeloid cells. Blood 117: 6532-6541, 2011.

97. Wing K, Fehérvári Z and Sakaguchi S: Emerging possibilities in the development and function of regulatory T cells. Int Immunol 18: 991-1000, 2006.

98. Rieber N, Gille C, Köstlin N, Schäfer I, Spring B, Ost M, Spieles H, Kugel HA, Pfeiffer M, Heininger V, et al: Neutrophilic myeloid-derived suppressor cells in cord blood modulate innate and adaptive immune responses. Clin Exp Immunol 174: 45-52, 2013.

99. Rieber N, Brand A, Hector A, Graepler-Mainka U, Ost M, Schäfer I, Wecker I, Neri D, Wirth A, Mays L, et al: Flagellin induces myeloid-derived suppressor cells: Implications for Pseudomonas aeruginosa infection in cystic fibrosis lung disease. J Immunol 190: 1276-1284, 2013

100. Rieber N, Wecker I, Neri D, Fuchs K, Schäfer I, Brand A,Pfeiffer M, Lang P, Bethge W, Amon O, et al: Extracorporeal photopheresis increases neutrophilic myeloid-derived suppressor cells in patients with GvHD. Bone Marrow Transplant 49: 545-552, 2014

101. Huang B, Pan PY, Li Q, Sato AI, Levy DE, Bromberg J, Divino CM and Chen SH: Gr- $1^{+} \mathrm{CD} 115^{+}$immature myeloid suppressor cells mediate the development of tumor-induced $\mathrm{T}$ regulatory cells and T-cell anergy in tumor-bearing host. Cancer Res 66: 1123-1131, 2006.

102. Serafini P, Mgebroff S, Noonan K and Borrello I: Myeloid-derived suppressor cells promote cross-tolerance in B-cell lymphoma by expanding regulatory T cells. Cancer Res 68: 5439-5449, 2008.

103. Yang R, Cai Z, Zhang Y, Yutzy WH IV, Roby KF and Roden RB CD80 in immune suppression by mouse ovarian carcinoma-associated $\mathrm{Gr}-1^{+} \mathrm{CD} 11 \mathrm{~b}^{+}$myeloid cells. Cancer Res 66: 6807-6815 2006.

104. Luan Y, Mosheir E, Menon MC, Wilson D, Woytovich C, Ochando J and Murphy B: Monocytic myeloid-derived suppressor cells accumulate in renal transplant patients and mediate CD4 Foxp3 ${ }^{+}$Treg expansion. Am J Transplant 13: 3123-3131, 2013.

105. Schlecker E, Stojanovic A, Eisen C, Quack C, Falk CS, Umansky V and Cerwenka A: Tumor-infiltrating monocytic myeloid-derived suppressor cells mediate CCR5-dependent recruitment of regulatory T cells favoring tumor growth. J Immunol 189: 5602-5611, 2012.

106. Pan PY, Ma G, Weber KJ, Ozao-Choy J, Wang G, Yin B, Divino CM and Chen SH: Immune stimulatory receptor CD40 is required for T-cell suppression and T regulatory cell activation mediated by myeloid-derived suppressor cells in cancer. Cancer Res 70: 99-108, 2010.

107. Chou HS, Hsieh CC, Yang HR, Wang L, Arakawa Y, Brown K, Wu Q, Lin F, Peters M, Fung JJ, et al: Hepatic stellate cells regulate immune response by way of induction of myeloid suppressor cells in mice. Hepatology 53: 1007-1019, 2011.

108. Mildner A, Mack M, Schmidt H, Brück W, Djukic M, Zabel MD, Hille A, Priller J and Prinz M: CCR2 ${ }^{+}$Ly-6Chi monocytes are crucial for the effector phase of autoimmunity in the centra nervous system. Brain 132: 2487-2500, 2009.

109. Yin B, Ma G, Yen CY, Zhou Z, Wang GX, Divino CM, Casares S, Chen SH, Yang WC and Pan PY: Myeloid-derived suppressor cells prevent type 1 diabetes in murine models. J Immunol 185 : 5828-5834, 2010.
110. Marhaba R, Vitacolonna M, Hildebrand D, Baniyash M, Freyschmidt-Paul P and Zöller M: The importance of myeloid-derived suppressor cells in the regulation of autoimmune effector cells by a chronic contact eczema. J Immunol 179: 5071-5081, 2007

111. Westendorf AM, Fleissner D, Deppenmeier S, Gruber AD, Bruder D, Hansen W, Liblau R and Buer J: Autoimmune-mediated intestinal inflammation-impact and regulation of antigen-specific CD8 ${ }^{+} \mathrm{T}$ cells. Gastroenterology 131: 510-524, 2006.

112. Crook K, Weeks M, Rampersad R, Baldi R and Liu P: Myeloid-derived suppressor cells ameliorate the pathogenesis of autoimmune arthritis (P1058). J Immunol 190: 185-193, 2013.

113. Kanterman J, Sade-Feldman M and Baniyash M (eds): New insights into chronic inflammation-induced immunosuppression. In: Seminars in Cancer Biology. Vol 22. 4th edition. Academic Press, Cambridge, MA, pp307-318, 2012.

114. Zamarron BF and Chen W: Dual roles of immune cells and their factors in cancer development and progression. Int J Biol Sci 7: 651-658, 2011

115. Ustun C, Miller JS, Munn DH, Weisdorf DJ and Blazar BR: Regulatory T cells in acute myelogenous leukemia: Is it time for immunomodulation?. Blood 118: 5084-5095, 2011.

116. Vanneman M and Dranoff G: Combining immunotherapy and targeted therapies in cancer treatment. Nat Rev Cancer 12: 237-251, 2012.

117. Highfill SL, Rodriguez PC, Zhou Q, Goetz CA, Koehn BH, Veenstra R, Taylor PA, Panoskaltsis-Mortari A, Serody JS, Munn DH, et al: Bone marrow myeloid-derived suppressor cells (MDSCs) inhibit graft-versus-host disease (GVHD) via an arginase-1-dependent mechanism that is up-regulated by interleukin-13. Blood 116: 5738-5747, 2010

118. Zhou Z, French DL, Ma G, Eisenstein S, Chen Y, Divino CM, Keller G, Chen SH and Pan PY: Development and function of myeloid-derived suppressor cells generated from mouse embryonic and hematopoietic stem cells. Stem Cells 28: 620-632, 2010

119. Hsieh CC, Chou HS, Yang HR, Lin F, Bhatt S, Qin J, Wang L, Fung JJ Qian S and Lu L: The role of complement component 3 (C3) in differentiation of myeloid-derived suppressor cells. Blood 121, 1760-1768, 2013

120. Wang Y, Tian J and Wang S (eds): The potential therapeutic role of myeloid-derived suppressor cells in autoimmune arthritis. In: Seminars in Arthritis and Rheumatism. Vol 45. 4th Edition. WB Saunders, Philadelphia, PA, pp490-495, 2016.

121. Anderson AE, Sayers BL, Haniffa MA, Swan DJ, Diboll J, Wang XN, Isaacs JD and Hilkens CM: Differential regulation of naive and memory $\mathrm{CD} 4^{+} \mathrm{T}$ cells by alternatively activated dendritic cells. J Leukoc Biol 84: 124-133, 2008.

122. Steinman RM, Hawiger D and Nussenzweig MC: Tolerogenic dendritic cells. Annu Rev Immunol 21: 685-711, 2003.

123. Thomson AW and Robbins PD: Tolerogenic dendritic cells for autoimmune disease and transplantation. Ann Rheum Dis 67 (Suppl 3): iii90-iii96, 2008.

124. Naiditch H, Shurin MR and Shurin GV: Targeting myeloid regulatory cells in cancer by chemotherapeutic agents. Immunol Res 50: 276-285, 2011.

125. Wada Y, Hisamatsu T, Kamada N, Okamoto S and Hibi T: Retinoic acid contributes to the induction of IL-12-hypoproducing dendritic cells. Inflamm Bowel Dis 15: 1548-1556, 2009.

126. Soroosh P, Doherty TA, Duan W, Mehta AK, Choi H, Adams YF, Mikulski Z, Khorram N, Rosenthal P, Broide DH and Croft M: Lung-resident tissue macrophages generate Foxp $3^{+}$regulatory $\mathrm{T}$ cells and promote airway tolerance. J Exp Med 210: 775-788, 2013.

127. Weber MS, Prod'homme T, Youssef S, Dunn SE, Rundle CD, Lee L, Patarroyo JC, Stüve O, Sobel RA, Steinman L and Zamvil SS: Type II monocytes modulate T cell-mediated central nervous system autoimmune disease. Nat Med 13: 935-943, 2007.

128. Kavousanaki M, Makrigiannakis A, Boumpas D and Verginis P: Novel role of plasmacytoid dendritic cells in humans: Induction of interleukin-10-producing Treg cells by plasmacytoid dendritic cells in patients with rheumatoid arthritis responding to therapy. Arthritis Rheum 62: 53-63, 2010.

129. Yazawa T, Shibata M, Gonda K, Machida T, Suzuki S, Kenjo A, Nakamura I, Tsuchiya T, Koyama Y, Sakurai K, et al: Increased IL-17 production correlates with immunosuppression involving myeloid-derived suppressor cells and nutritional impairment in patients with various gastrointestinal cancers. Mol Clin Oncol 1: 675-679, 2013. 